\title{
BMJ Open Development and validation of a Japanese version of the Patient Centred Assessment Method and its user guide: a cross-sectional study
}

\author{
Rieko Mutai (D) , ${ }^{1,2}$ Yoshifumi Sugiyama (D) , ${ }^{1}$ Shuhei Yoshida (D) , $, 3,4,5$ \\ Ryoko Horiguchi, ${ }^{1}$ Takamasa Watanabe, ${ }^{1,3,4}$ Makoto Kaneko, ${ }^{1,3,6,7}$ \\ Tomokazu Tominaga, ${ }^{1,3,6,8}$ Daichi Hayashi, ${ }^{9}$ Masato Matsushima ${ }^{1}$
}

To cite: Mutai R, Sugiyama Y, Yoshida S, et al. Development and validation of a Japanese version of the Patient Centred Assessment Method and its user guide: a crosssectional study. BMJ Open 2020;10:e037282. doi:10.1136/ bmjopen-2020-037282

- Prepublication history and additional material for this paper are available online. To view these files, please visit the journal online (http://dx.doi. org/10.1136/bmjopen-2020037282).

Received 27 January 2020 Revised 08 November 2020 Accepted 09 November 2020

Check for updates

(C) Author(s) (or their employer(s)) 2020. Re-use permitted under CC BY-NC. No commercial re-use. See rights and permissions. Published by BMJ.

For numbered affiliations see end of article.

Correspondence to Dr Masato Matsushima; masato@jikei.ac.jp

\section{ABSTRACT}

Objectives The primary objective of this study was to develop the Japanese version of the Patient Centred Assessment Method (PCAM) and its user guide. The secondary objective was to examine the validity and reliability in the primary care setting.

Design Cross-sectional study.

Setting Three family physician teaching clinics located in urban residential areas in Tokyo, Japan.

Participants Patients who were aged 20 years or older, and who had an appointment with physicians at the three participating clinics.

Main outcome measures Patient complexity measured by PCAM and complexity/burden level measured by a Visual Analogue Scale (VAS).

Results Although confirmatory factor analysis using a model described in a previous study revealed that the indices did not meet the criteria for good fit, exploratory factor analysis revealed a new three-factor structure of 'Personal well-being,' 'Social interaction' and 'Needs for care/service.' Cronbach's alpha of PCAM was 0.86 . Spearman's rank correlation coefficients between PCAM scores and VAS scores were 0.51 for complexity $(p<0.001)$ and 0.41 for burden $(p<0.001)$. There were 42 patients (14.3\% of total patients) with PCAM scores greater than its mean of 16.5 but with complexity VAS scores less than its mean of 20.8 .

Conclusions The Japanese version of PCAM and its user guide were developed through Japanese translation and cultural adaptation by cognitive debriefing. PCAM is a valid and reliable tool to assess patient complexity in the primary care settings in Japan. Additionally, although the correlation between total PCAM scores and complexity/ burden as assessed by VAS was moderate, PCAM can more precisely identify patient complexity than skilled physician's intuition.

\section{INTRODUCTION}

Social and economic conditions are associated with human health and have been termed social determinants of health. ${ }^{1}$ Developed countries are now increasingly facing many obstacles caused by changes in the population
Strengths and limitations of this study

This is the first study to develop a Japanese version of the Patient Centred Assessment Method.

- In addition to the scale itself, we also developed a Japanese user guide through forward translation, back-translation and cognitive debriefing for cultural adaptation.

- The criterion validity was somewhat limited because we substituted Visual Analogue Scales for the external criteria.

- Generalisability may be limited given that only three clinics in urban areas participated.

pyramid, declining birthrates and ageing populations. ${ }^{2}$ These demographic shifts are leading to a growing number of people with diverse and complex backgrounds, such as multimorbidity, ${ }^{3-5}$ neuropsychiatric diseases including dementia ${ }^{67}$ and depression, ${ }^{8-10}$ less involvement in social networks ${ }^{11} 12$ and living alone. ${ }^{13}$ Therefore, the role of primary care providers in addressing these patients' biopsychosocial complexities is becoming more important.

INTERMED $^{14-16}$ is an instrument that was developed to assess patient complexity in secondary care settings, and the validity and reliability of the Japanese version have been verified. ${ }^{17}$ Based on INTERMED, the Minnesota Complexity Assessment Method (MCAM) ${ }^{18}$ was developed for use in the primary care settings, which led to an advanced version of MCAM, called the Minnesota Edinburgh Complexity Assessment Method (MECAM), ${ }^{19}$ for the assessment of patients' biopsychosocial needs.

The Patient Centred Assessment Method $(\mathrm{PCAM})^{20}$ is an improved version of MECAM that can be applied to long-term conditions such as chronic obstructive pulmonary 
disease, diabetes mellitus and coronary heart disease. The PCAM, a practical tool for identifying and assessing biopsychosocial problems, enables healthcare professionals to prioritise patients' needs in accordance with their severity and level of urgency. ${ }^{20}$ The PCAM comprises four categories: 'Health and well-being,' 'Social environment,' 'Health literacy and communication' and 'Service coordination. ${ }^{21}$ In previous studies, we assessed and confirmed the validity and reliability of the original version of PCAM in the initial phase of the secondary care setting in Japan and identified a correlation between total PCAM scores and length of hospital stay ${ }^{22} /$ degree of burden on medical staff. ${ }^{23}$

As stated above, the PCAM allows medical providers to assess patients' needs from biopsychosocial perspectives and to make referrals to a broader range of services. ${ }^{20}$ In Japan, assessing patient complexity and acting on that basis have recently drawn considerable attention. One example is social prescribing, which has the potential to improve patients' health outcomes by linking them to appropriate services. ${ }^{24}$ Additionally, the PCAM promotes sharing of information, which enables seamless interventions by physicians, nurses and other healthcare professionals. For example, in Japan, establishment of a care delivery system by multidisciplinary collaboration is encouraged, the aim being to facilitate provision of comprehensive and continuous care to patients and their families. ${ }^{25}$ The PCAM is an indispensable tool for interprofessional information sharing. However, until now no Japanese equivalent for identifying and evaluating patient complexity has been available. A Japanese version of PCAM would be useful for healthcare professionals who are not proficient in English in that it would encourage and empower them to consider various biopsychosocial perspectives. The primary objective of this study was to develop a Japanese version of PCAM and its user guide. The secondary objective was to examine the validity and reliability in the primary care setting in Japan

\section{METHODS}

This study consisted of two phases. In the first phase, the Japanese version of PCAM and its user guide were developed. In the second phase, the validity and reliability of the Japanese version of PCAM were evaluated in the primary care setting. In this study, we examined structural and criterion validity and internal consistency as reliability.

\section{First phase: development of the Japanese version of PCAM and its user guide}

PCAM and its user guide were translated into and culturally adapted to Japanese with the original author's permission in accordance with the guidelines of the WHO and International Society Pharmacoeconomics and Outcomes Research Task Force for Translation. ${ }^{26}{ }^{27}$ First, the primary investigator (RM), who was a native speaker of Japanese, translated the original PCAM and its user guide into Japanese, and four researchers (RM, MM, SY, HW) discussed cultural adaptation to Japanese and completed the provisional versions. Next, a bilingual medical doctor (DH), who was not familiar with the original PCAM and its user guide, back-translated the provisional versions into English. Then, discrepancies between the original and back-translated English version were reviewed and revised by the original authors and three of the authors of this study (RM, MM, SY). Thus, we completed the prototype versions. Next, cognitive debriefing on the prototype versions was conducted in a small group to check alternative wording and to confirm the understandability, interpretation and cultural relevance of the translation. Five Japanese physicians were recruited from primary care clinics in Tokyo, Japan by means of snowball sampling considering age, sex and years of experience, and were interviewed to check and confirm each of the points described above.

\section{Second phase: evaluation of validity and reliability \\ Study design and setting}

This was a cross-sectional study reported in accordance with the Strengthening the Reporting of Observational Studies in Epidemiology Statement. ${ }^{28}$ This study was conducted at three family physician teaching clinics located in urban residential areas in Tokyo, Japan that were responsible for primary care with group practice: Kitaadachi-seikyo Clinic, Seikyo-ukima Clinic and Musashikoganei Clinic affiliated with Japanese Health and Welfare Co-operative Federation.

\section{Patient participants}

Patients who were aged 20 years or older, and who had an appointment with physicians at the three participating clinics were consecutively included. Exclusion criteria were patients for a general check-up, patients who had difficulty communicating in Japanese, patients who were too sick to complete the questionnaire or patients who declined to participate in this study.

\section{Data collection}

Data were collected by five physicians: two at Kitaadachiseikyo Clinic, one at Seikyo-ukima Clinic and two at Musashikoganei Clinic, Japanese Health and Welfare Co-operative Federation. The period for data collection was between 5th January 2018 and 25th July 2018 in consideration of the physicians' and the principal investigator's schedule: 5 days at Kitaadachi-seikyo Clinic, 15 days at Seikyo-ukima Clinic and 12 days at Musashikoganei Clinic. In advance of the data collection, the principal investigator explained the Japanese version of the PCAM to the five physicians using the user guide to standardise the criteria of evaluation. Patients were asked to complete a self-administered questionnaire on demographic characteristics while waiting for a consultation at the clinic; furthermore, physicians evaluated the degree of complexity and burden using a Visual Analogue Scale (VAS).$^{29}$ During or after a consultation, physicians 
used the Japanese version of the PCAM user guide and completed a PCAM form.

\section{Outcome measures}

Patient Centred Assessment Method

PCAM consists of 12 items across four categories ${ }^{21}$ : 'Health and well-being' (four items: 'Physical health needs,' 'Physical health impacting mental well-being,' 'Lifestyle impacting mental well-being' and 'Other mental well-being'), 'Social environment' (four items: 'Home environment,' 'Daily activities,' 'Social network' and 'Financial resources'), 'Health literacy and communication' (two items: 'Health literacy' and 'Engagement in discussion') and 'Service coordination' (two items: 'Other services' and 'Service coordination'). Each item is scored from 1 to 4 points, with total scores ranging from 12 to 48 points. The higher the score, the more complex the patient.

\section{Complexity/burden level measured by VAS}

Physicians possibly misperceive the psychological 'burden' of caring for a patient with complex needs as intuitive patient 'complexity.' Therefore, patient complexity and psychological burden were measured separately, enabling the physicians to be aware of the difference between them and to evaluate them precisely. Measurements were performed by using a VAS. The VAS for 'complexity' comprised a $10 \mathrm{~cm}$ long horizontal line with a starting point of 'not complex' ( 0 point) and an ending point of 'the most complex' (100 points). The VAS for 'burden' similarly comprised a $10 \mathrm{~cm}$ long horizontal line with a starting point of 'no burden' (0 point) and an ending point of 'the heaviest burden' (100 points). A person who was blinded to the patients' information measured the length marked on the VASs.

There are currently no external criteria for examining criterion validity for which the validity and reliability have been established in the primary care setting. Therefore, a VAS, which is a practical tool, was substituted for external criteria.

\section{Patient characteristics}

Demographic characteristics including sex, age, marital status, household composition, household size, home ownership, years of residence, employment status and educational background were obtained from a selfadministered questionnaire, whereas main diseases, Charlson Comorbidity Index (CCI) ${ }^{30} 31$ and copayment (the proportion of individual payment of medical expense depending on age and income) were obtained from medical records. Physicians chose one main disease from all of a patient's diseases for that patient's regular clinical visits.

\section{Sample size calculation}

The recommended subjects-to-variables ratio is from 3:1 to 20:1 when conducting exploratory factor analysis. ${ }^{32}$ Because a larger sample size has been reported to provide more precise results in factor analysis, the ratio of 20:1 was employed in this study. Therefore, because PCAM includes 12 items, the sample size was determined to be 300 in consideration of at most 60 participants having missing values.

\section{Statistical analysis}

Confirmatory factor analysis with the robust maximum likelihood estimation was conducted to assess structural validity, assuming a two-factor model of medicine-oriented and patient-oriented complexity, which was derived from our previous study. ${ }^{21}$ The model fit was judged to be good if the comparative fit index (CFI) was $\geq 0.90$, standardised root mean residual (SRMR) was $\leq 0.08$ and root mean squared error of approximation (RMSEA) was $\leq 0.08$. $^{33}$

When the model fit was insufficient, exploratory factor analysis with the robust maximum likelihood estimation and CF-Equamax rotation was performed. Parallel analysis was conducted to determine the number of common factors and factor loading $\geq 0.4$ was adopted to determine which items to include.

Internal consistency was considered adequate if Cronbach's alpha was between 0.70 and $0.95 .^{34}$

Spearman's rank correlation coefficient between total PCAM scores and complexity/burden as measured by VAS examined criterion validity and how closely the scale correlated with the physicians' general impressions. ${ }^{35}$

All statistical analyses were performed using Stata/SE V.14.0 ${ }^{36} 37$ and Mplus V.8.4. ${ }^{38}{ }^{39} \mathrm{P}$ values of $<0.05$ were considered statistically significant.

\section{Patient and public involvement}

This study was conducted without patient or the public involvement: they had no role in the study design; the data analysis and interpretation; the manuscript preparation and reviewing; or the decision to submit the manuscript.

\section{RESULTS}

Japanese translation and cultural adaptation by cognitive debriefing

After the Japanese forward and backward translation process, cultural adaptation was conducted by interviewing one female physician and four male physicians between 27th April and 18th May 2017. These five physicians' median (IQR) age and years of experiences as a primary care physician were 37 (34-38) and $12(10-14)$ years, respectively. The median interview time (IQR) was $51(17-55) \mathrm{min}$. The physicians pointed out 34 parts that required improvement; modification of these parts was subsequently discussed by the researchers. For example, the wording of the sample questions to patients in the user guide was changed from a literary to a colloquial style to make them easier to understand. Terms with the same pronunciation but different Chinese characters with different meanings were changed to avoid confusion. Twelve of the 34 modified parts were back-translated to minimise possible loss of the original meaning caused by the modification. Three were back-translated into exactly 
Table 1 Patient characteristics

\begin{tabular}{|c|c|}
\hline Age, mean (SD) (years) & $72.4(11.4)$ \\
\hline Women, n (\%) & $164(56.0)$ \\
\hline Married, n (\%) & $178(60.8)$ \\
\hline \multicolumn{2}{|l|}{ Household composition, n (\%) } \\
\hline Single & $70(23.9)$ \\
\hline Married couple & $92(31.4)$ \\
\hline Other & $131(44.7)$ \\
\hline \multicolumn{2}{|l|}{ Living arrangements, n (\%) } \\
\hline Living alone & $70(23.9)$ \\
\hline Cohabiting & $223(76.1)$ \\
\hline \multicolumn{2}{|l|}{ Home ownership, n (\%) } \\
\hline Owned & $177(60.4)$ \\
\hline Rented & $116(39.6)$ \\
\hline Years of residence, mean (SD) (years) & $28.4(17.4)$ \\
\hline \multicolumn{2}{|l|}{ Employment status, n (\%) } \\
\hline Full-time employment & $45(15.4)$ \\
\hline Part-time employment & $28(9.6)$ \\
\hline Unemployment/homemaker & $166 / 36(56.7 / 12.3)$ \\
\hline Other & $18(6.1)$ \\
\hline \multicolumn{2}{|l|}{ Academic background, $\mathrm{n}(\%)$} \\
\hline Junior high school & $85(29.0)$ \\
\hline High school & $107(36.5)$ \\
\hline Junior college/vocational school & $51(17.4)$ \\
\hline University & $44(15.0)$ \\
\hline Graduate school & $6(2.0)$ \\
\hline \multicolumn{2}{|l|}{ Insurance copayment, n (\%) } \\
\hline $0 \%$ & $27(9.2)$ \\
\hline $10 \%$ & $134(45.7)$ \\
\hline $20 \%$ & $32(10.9)$ \\
\hline $30 \%$ & $100(34.1)$ \\
\hline $\mathrm{CCl}$, mean (SD) & $0.88(1.4)$ \\
\hline
\end{tabular}

$\mathrm{CCl}$, charlson comorbidity index.

the same as the original English text; four in the PCAM; and five in the user guide were confirmed and accepted by the original authors. Finally, the Japanese version of PCAM (see online supplemental file 1) and its user guide (see online supplemental file 2) were developed.

\section{Evaluation of validity and reliability}

A total of 298 eligible patients were recruited: 100 at Kitaadachi-seikyo Clinic, 101 at Seikyo-ukima Clinic and 97 at Musashikoganei Clinic. Physicians missed out the entire PCAM in four patients and part of it in one patient, which led to a total of 293 patients included in the final analysis. Patient characteristics and main diseases are shown in tables 1 and 2.

The mean (SD) PCAM score was 16.5 (5.1) and the median (IQR) score was 15 (13-18). As shown in figure 1,
Table 2 Main diseases diagnosed among patients

Classification of main diseases, $\mathrm{n}(\%)$

Infectious and parasitic diseases $1(0.3)$

Neoplasms

Diseases of the blood and blood-forming organs 4 (1.4) and certain disorders involving the immune mechanism

Endocrine, nutritional and metabolic diseases

$\begin{array}{ll}\text { Total } & 73(24.9) \\ \text { Diabetes mellitus } & 49 \\ \text { Dyslipidaemia } & 18\end{array}$

Mental and behavioural disorders

$\begin{array}{ll}\text { Total } & 15(5.1) \\ \text { Vascular and unspecified dementia } & 10 \\ \text { Sleep-wake disorders } & 4(1.4) \\ \text { Diseases of the nervous system } & 8(2.7) \\ \text { Diseases of the circulatory system } & 137(46.8) \\ \text { Total } & 111 \\ \text { Hypertension } & 20 \\ \text { Heart failure } & \\ \text { Diseases of the respiratory system } & 11(3.8) \\ \text { Total } & 6 \\ \text { COPD } & 4 \\ \text { Asthma } & \\ \text { Diseases of the digestive system } & 12(4.1) \\ \text { Total } & 6 \\ \text { GERD } & 1 \\ \text { IBS } & 4(1.4) \\ \text { Diseases of the skin and subcutaneous tissue }\end{array}$

Diseases of the musculoskeletal system and connective tissue

$\begin{array}{cl}\text { Total } & 10(3.4) \\ \text { Osteoporosis } & 7 \\ \text { Diseases of the genitourinary system } & 2(0.7)\end{array}$

Injury, poisoning and certain other consequences 1 (0.3) of external causes

Total 293 (100)

COPD, chronic obstructive pulmonary disease; GERD, gasoesophagial reflux disease; IBS, irritable bowel syndrome.

the distribution of total PCAM scores was skewed to the right with a floor effect.

\section{Confirmatory and exploratory factor analysis}

Confirmatory factor analysis using the model described in our previous study revealed the following indices for model fit: $\mathrm{CFI}=0.663, \mathrm{SRMR}=0.104$ and RMSEA $=0.134$.

Because the indices did not meet the criteria of good fit, exploratory factor analysis was performed. Parallel analysis suggested a maximum of six common factors. 


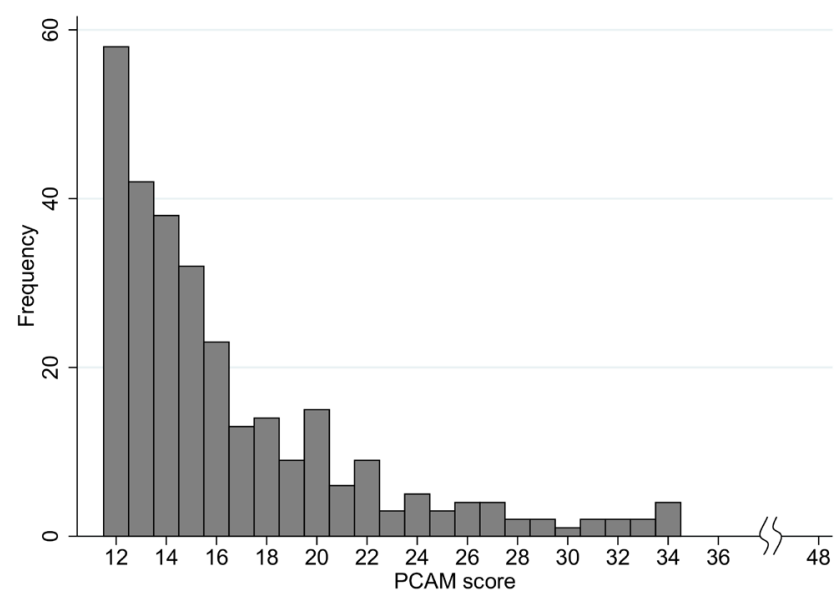

Figure 1 Distribution of total scores of PCAM. PCAM, Patient Centred Assessment Method.

However, because the four-factor to six-factor models included a common factor that comprised one item, a three-factor model was employed. The items 'Physical health needs,' 'Physical health impacting mental wellbeing,' 'Other mental well-being concerns' and 'Daily activities,' which focus on physical and mental well-being, contributed to the first factor, termed 'Personal wellbeing.' The items 'Social network,' 'Health literacy' and 'Engagement in discussion,' which focus mainly on interaction with social networks and healthcare professionals, contributed to the second factor, termed 'Social interaction.' The items 'Home environment,' 'Other services' and 'Service coordination,' which focus on patients' needs arising in the home environment and satisfied with social services, contributed to the third factor, termed 'Needs for care/service.'
However, the two items 'Lifestyle impacting mental well-being' and 'Financial resources' were not included due to a factor loading less than 0.4 (table 3 ).

Cronbach's alpha of PCAM was 0.86 , and that of the three factors: 'Personal well-being,' 'Social interaction' and 'Needs for care/service' were $0.77,0.78$ and 0.89 , respectively.

The correlation between PCAM and VAS (complexity and burden) is shown in figure 2. Spearman's rank correlation coefficients between PCAM scores and VAS were 0.51 for complexity $(\mathrm{p}<0.001)$ and 0.41 for burden $(\mathrm{p}<0.001)$. There were 42 patients ( $14.3 \%$ of total patients) with PCAM scores more than the mean score of 16.5 but with complexity scores less than the mean score of 20.8. Moreover, Spearman's rank correlation coefficient between complexity and burden was 0.77 .

\section{DISCUSSION}

In this study, a Japanese version of the PCAM and its user guide were developed through a process of translation, back-translation and cognitive debriefing. Then, the structural validity of the Japanese version of the PCAM was assessed through exploratory factor analysis, which revealed the three new factors of 'Personal wellbeing,' 'Social interaction' and 'Needs for care/service,' although confirmatory factor analysis using the model described in our previous study showed the model fit to be poor. Cronbach's alpha of PCAM, 'Personal well-being,' 'Social interaction' and 'Needs for care/service' were all high. Additionally, the total PCAM score was moderately correlated with complexity and burden as assessed by VAS, indicating that criterion validity was established to some extent.

Table 3 Exploratory factor analysis of the Japanese version of the Patient Centred Assessment Method

\begin{tabular}{|c|c|c|c|}
\hline & First factor & Second factor & Third factor \\
\hline \multicolumn{4}{|l|}{ Health and well-being } \\
\hline Physical health needs & 0.527 & 0.165 & 0.017 \\
\hline Lifestyle impacting mental well-being & 0.099 & 0.144 & 0.083 \\
\hline Other mental well-being concerns & 0.667 & -0.022 & 0.094 \\
\hline Home environment & 0.327 & 0.111 & 0.433 \\
\hline Daily activities & 0.659 & 0.010 & 0.084 \\
\hline Social network & 0.369 & 0.426 & 0.094 \\
\hline Financial resources & 0.307 & 0.120 & 0.236 \\
\hline \multicolumn{4}{|l|}{ Health literacy and communication } \\
\hline \multicolumn{4}{|l|}{ Service coordination } \\
\hline Other services & 0.020 & 0.056 & 0.915 \\
\hline Service coordination & 0.014 & 0.086 & 0.885 \\
\hline
\end{tabular}



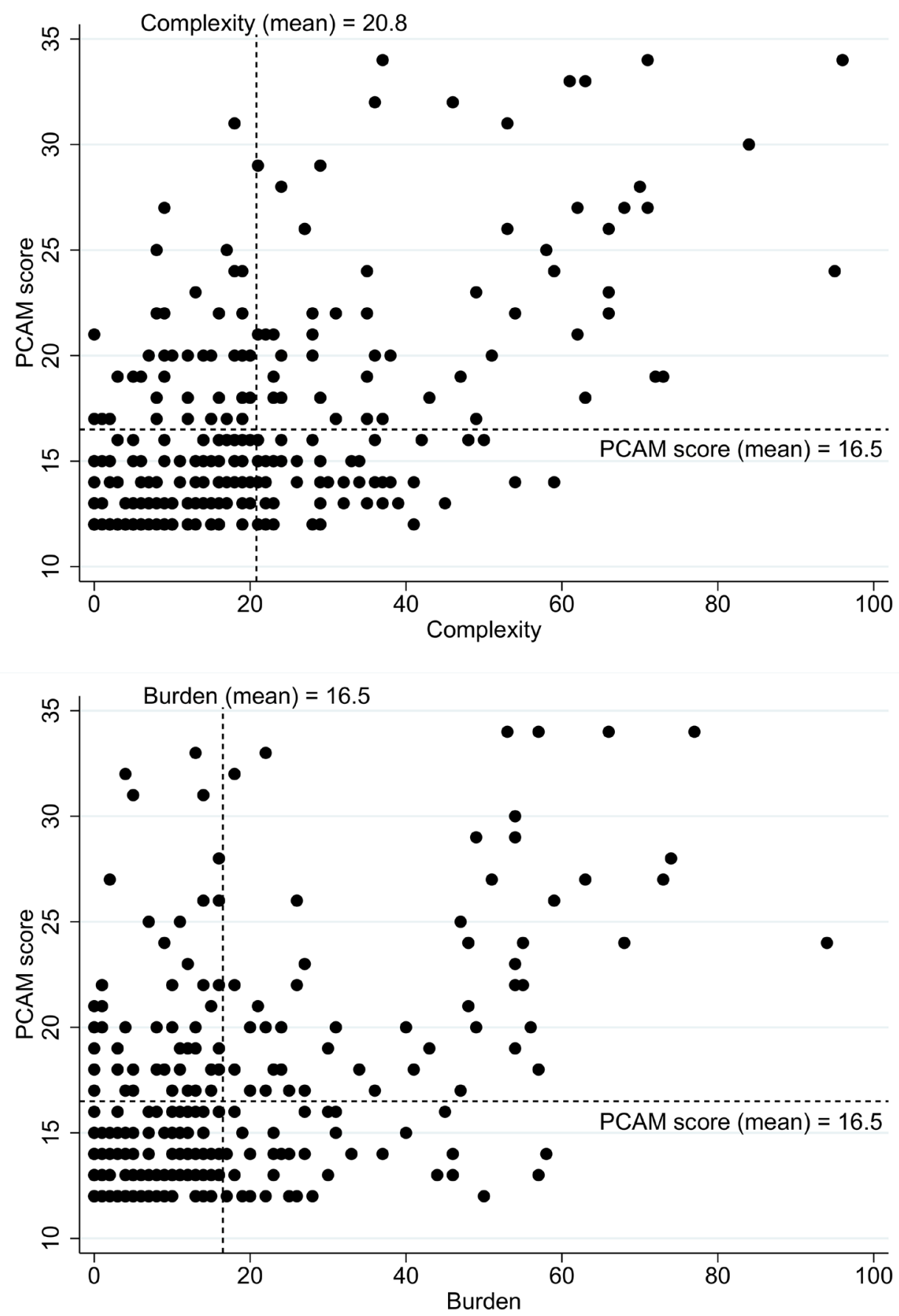

Figure 2 Correlation between PCAM scores and complexity/burden level measured by VAS. PCAM, Patient Centred Assessment Method; VAS, Visual Analogue Scale.

This study showed a three-factor structure that differed from that of our previous study, this difference presumably being attributable to differences between the clinical settings. Our previous study was conducted in the secondary care setting and the participants were inpatients of an acute hospital, ${ }^{21}$ whereas the current study was in the primary care setting. For example, one difference was that the mean (SD) CCI score was 0.9 (1.4) in the present study, which was lower than that of 2.0 (2.2) in our previous study ${ }^{21}$ with higher biomedical complexity. Furthermore, the mean (SD) age of patients in our previous study, 77.4
(11.9) years, was higher than that of the current study. In terms of factor structure, patients with greater physical health-related needs are likely to have greater needs for care and services, which could result in hospitalisation in the secondary care setting. Thus, the 'Medicineoriented' factor in the previous study includes both the item 'Physical health needs' and items that are included in the 'Needs for care/service' factor in the present study. Conversely, in the primary setting, such needs for care and services may not be identified because the patients have fewer physical health-related needs. Therefore, the 
item 'Physical health needs' was not included in the same factor as items that are included in the 'Needs for care/ service' factor. Rather, the item 'Physical health needs' was treated as a component of physical well-being and therefore included in the 'Personal well-being' factor in the present study. Additionally, the 'Patient-oriented' factor in the previous study includes the items 'Physical health impacting mental well-being,' 'Other mental well-being,' 'Daily activities,' 'Social network,' 'Health literacy' and 'Engagement in discussion,' whereas these items were divided into two factors, 'Personal well-being' and 'Social interaction,' in the present study. This is probably because primary care physicians take care of people in the community and focus more on assessing their patients from social perspectives. In contrast, social aspects of hospitalised patients are less important in the secondary setting, where social aspects are combined with biopsychological factors in the 'Patient-oriented' factor in the previous study.

The extraction of 'Social interaction' and 'Needs for care/service' from 'Personal well-being', which is mainly related to physical and psychological well-being, was of particular importance. 'Social interaction' includes items regarding 'Social network' and 'Health literacy and communication.' Health literacy is the cognitive and social ability to obtain, understand, assess and use information that is essential for good health, ${ }^{40}$ and consists of basic/functional, communicative/interactive and critical literacy ${ }^{41}$; in particular, communicative/ interactive literacy is necessary for active participation in social networks. Therefore, it was consistent and reasonable to extract issues related to both social network and health literacy/communication as a common factor. On the other hand, 'Needs for care/service' includes items regarding 'Home environment' and 'Service coordination.' The PCAM evaluates 'Home environment' in terms of safety and stability. ${ }^{21}$ In Japan, the population is rapidly ageing, causing many related problems. For example, older adults are obliged to take care of their old spouses. The numbers of households with a single older adult and solitary deaths are increasing. ${ }^{42}{ }^{43}$ These problems that are attributable to an unsafe or unstable home environment, which may be solvable with nursing care and social welfare interventions, are assumed to be strongly associated with 'Service coordination.'

However, two items, 'Lifestyle impacting mental wellbeing' and 'Financial resources', had insufficient factor loading less than 0.4 and were not included in the three factors. The exclusion of the former item presumably resulted from the fact that $60 \%$ of all patients had lifestyle diseases such as diabetes mellitus, dyslipidaemia and hypertension, which were generally well controlled at the participating clinics; therefore, the impact of a patient's lifestyle on these diseases might have been underestimated. Additionally, severely alcoholic patients and drug misusers were possibly referred to specialised facilities, which could also have resulted in underestimation of this item. The exclusion of the latter item presumably resulted from the fact that copayment of medical expenses is at most $30 \%$ under the Japanese universal health insurance coverage system and $0 \%$ under the welfare system ${ }^{44}{ }^{45}$; hence, few patients were likely troubled with financial problems due to healthcare. Moreover, previous research revealed that financial topics are taboo and inappropriate for discussion with healthcare providers ${ }^{46}$; therefore, this question might not have been answered accurately. In the Japanese version of PCAM, these items were not intentionally excluded in consideration of the fact that the overall Cronbach's alpha was 0.86 , which indicates a high internal consistency without exclusion of these items. The fact that lifestyle-related and economic problems negatively influence physical and psychological conditions is established. ${ }^{47} 48$ These two items should therefore not be excluded at this stage; further cautious and prudent research is required to determine how best to accurately score and include them.

This study also showed a floor effect in the distribution of PCAM scores, whereas our previous study did not. The large number of patients, in fact, had low patient complexity; however, physicians might not be able to distinguish detailed factors related to subtle patient complexity due to limited consultation time.

The correlation between total PCAM scores and complexity/burden as assessed by the VAS was found to be moderate. Although complexity and burden were separately assessed to prevent physicians from confusing these two variables, Spearman's rank correlation coefficient between complexity and burden was high. This indicates that physicians do not regard complexity as an objective index, but rather handle it as subjective feeling, or burden. Furthermore, patients that physicians regarded as being not complex were found to have somewhat high PCAM scores, even though physicians working at family physician teaching clinics are generally well trained to see patients from biopsychosocial perspectives. Accordingly, PCAM can more objectively and precisely identify patient complexity than skilled physician's intuition.

There are some limitations in this study. First, only three clinics in urban areas in Tokyo were included as study settings, which could have limited the generalisability of our findings. Second, inter-rater variability of PCAM scores was not evaluated. Patients were not assessed by two physicians because they usually visited the same primary care physician. We considered it would be unethical to force them to see an unfamiliar physician and undergo another PCAM assessment due to their temporal, economic and psychological burden. Moreover, some of the clinics had only one physician on service at a time. As a result, PCAM scores might have been overestimated or underestimated. However, a Japanese version of PCAM is necessary for healthcare providers to address biopsychosocial problems without language barriers, which outweighs the above study limitations. 


\section{CONCLUSION}

The Japanese version of PCAM and its user guide were developed Japanese translation and cultural adaptation by cognitive debriefing. PCAM was found to be a valid and reliable tool to assess patient complexity in the primary care setting in Japan. Additionally, although the correlation between total PCAM scores and complexity/ burden as assessed by the VAS was moderate, PCAM can more precisely identify patient complexity than skilled physician's intuition.

\section{Author affiliations}

${ }^{1}$ Division of Clinical Epidemiology, Research Center for Medical Sciences, The Jikei University School of Medicine, Tokyo, Japan

${ }^{2}$ Department of Adult Nursing, The Jikei University School of Nursing, Chofu, Japan ${ }^{3}$ Centre for Family Medicine Development, Japanese Health and Welfare $\mathrm{C}_{0}-$ operative Federation, Tokyo, Japan

${ }^{4}$ Kitaadachi-seikyo Clinic, Japanese Health and Welfare Co-operative Federation, Tokyo, Japan

${ }^{5}$ Department of Community-Based Medical System, Graduate School of Biomedical and Health Sciences, Hiroshima University, Hiroshima, Japan

${ }^{6}$ Musashikoganei Clinic, Japanese Health and Welfare Co-operative Federation, Koganei, Japan

${ }^{7}$ Department of Family and Community Medicine, Hamamatsu University School of Medicine, Hamamatsu, Japan

${ }^{8}$ Koganei Family Clinic, Koganei, Japan

${ }^{9}$ Department of Radiology, Stony Brook Medicine, Stony Brook, New York, USA

\section{Twitter Makoto Kaneko @makoto_knk}

Acknowledgements The authors are grateful to the members of the Division of Clinical Epidemiology, Research Center for Medical Sciences and The Jikei University School of Medicine for their kind advice on this study. The authors also thank Dr Yusuke Shigeshima for collecting the data and Mr Yuta Yamauchi for processing the data.

Contributors RM designed the study; collected, analysed and interpreted the data; and prepared and reviewed the manuscript. YS analysed and interpreted the data; and prepared and reviewed the manuscript. MM designed the study; analysed and interpreted the data; and prepared and reviewed the manuscript. SY designed the study; collected and interpreted the data; and reviewed the manuscript. $\mathrm{RH}$ designed the study; analysed and interpreted the data; and reviewed the manuscript. MK, TW and TT designed the study; collected the data and reviewed the manuscript. DH back-translated PCAM and its user guide and reviewed the manuscript.

Funding This study was supported by The Jikei University Research Fund for Graduate Students (grant number: N/A).

Disclaimer The sponsor of this study had no role in the study design; the data collection, analysis and interpretation; the manuscript preparation and reviewing; or the decision to submit the manuscript.

Competing interests MM received lecture fees and lecture travel fees from the Centre for Family Medicine Development of Japanese Health and Welfare Co-operative Federation. MM is an adviser of the Centre for Family Medicine Development practice-based research network. MM is a program director of The Jikei Clinical Research Program for Primary-care. YS, SY, MK, TW and TT are former trainees of The Jikei Clinical Research Program for Primary-care. TW currently is and SY, MK and TT used to be family physicians at the Centre for Family Medicine Development of Japanese Health and Welfare Co-operative Federation. RM, RH and DH have nothing to disclose.

Patient consent for publication Not required.

Ethics approval The research protocol for the first phase was approved by the Ethics Committee of The Jikei University School of Medicine (ethics number: 28-365 (8608)). The research protocol for the second phase was approved by the Ethics Committee of The Jikei University School of Medicine (ethics number: 29-229 (8845)) and Tokyo Hokuto Health Co-operative (ethics number: 89). The principal investigator (RM), who was not associated with any of the three family physician teaching clinics, fully explained the content of this study to all subjects; they then provided written informed consent to participate.
Provenance and peer review Not commissioned; externally peer reviewed.

Data availability statement № data are available.

Supplemental material This content has been supplied by the author(s). It has not been vetted by BMJ Publishing Group Limited (BMJ) and may not have been peer-reviewed. Any opinions or recommendations discussed are solely those of the author(s) and are not endorsed by BMJ. BMJ disclaims all liability and responsibility arising from any reliance placed on the content. Where the content includes any translated material, BMJ does not warrant the accuracy and reliability of the translations (including but not limited to local regulations, clinical guidelines, terminology, drug names and drug dosages), and is not responsible for any error and/or omissions arising from translation and adaptation or otherwise.

Open access This is an open access article distributed in accordance with the Creative Commons Attribution Non Commercial (CC BY-NC 4.0) license, which permits others to distribute, remix, adapt, build upon this work non-commercially, and license their derivative works on different terms, provided the original work is properly cited, appropriate credit is given, any changes made indicated, and the use is non-commercial. See: http://creativecommons.org/licenses/by-nc/4.0/.

\section{ORCID iDs}

Rieko Mutai http://orcid.org/0000-0002-4250-8027

Yoshifumi Sugiyama http://orcid.org/0000-0002-8522-6935

Shuhei Yoshida http://orcid.org/0000-0002-6747-1857

\section{REFERENCES}

1 World Health Organization, Regional Office for Europe. Social determinants of health: the solid facts - second edition, 2003. Available: https://apps.who.int/iris/bitstream/handle/10665/326568/ 9289013710eng. pdf?sequence $=1$ \&isAllowed $=y$

2 United Nations, Department of Economic and Social Affairs, Population Division. World population prospects 2019: highlights, 2019. Available: https://population.un.org/wpp/Publications/Files/ WPP2019_Highlights.pdf

3 Salisbury C, Johnson L, Purdy S, et al. Epidemiology and impact of multimorbidity in primary care: a retrospective cohort study. Br J Gen Pract 2011;61:e12-21.

4 France EF, Wyke S, Gunn JM, et al. Multimorbidity in primary care: a systematic review of prospective cohort studies. $\mathrm{Br} J$ Gen Pract 2012;62:e297-307.

5 Mitsutake S, Ishizaki T, Teramoto C, et al. Patterns of co-occurrence of chronic disease among older adults in Tokyo, Japan. Prev Chronic Dis 2019;16:E11.

6 Prince M, Bryce R, Albanese E, et al. The global prevalence of dementia: a systematic review and metaanalysis. Alzheimers Dement 2013;9:63-75.

7 Ohara T, Hata J, Yoshida D, et al. Trends in dementia prevalence, incidence, and survival rate in a Japanese community. Neurology 2017:88:1925-32.

8 Read JR, Sharpe L, Modini M, et al. Multimorbidity and depression: a systematic review and meta-analysis. J Affect Disord 2017;221:36-46.

9 Alexopoulos GS. Depression in the elderly. Lancet 2005;365:1961-70.

10 Mitchell PB, Harvey SB. Depression and the older medical patientwhen and how to intervene. Maturitas 2014;79:153-9.

11 Domènech-Abella J, Lara $\mathrm{E}$, Rubio-Valera $\mathrm{M}$, et al. Loneliness and depression in the elderly: the role of social network. Soc Psychiatry Psychiatr Epidemiol 2017;52:381-90.

12 Steptoe A, Shankar A, Demakakos P, et al. Social isolation, loneliness, and all-cause mortality in older men and women. Proc Natl Acad Sci U S A 2013;110:5797-801.

13 Ministry of Health, Labour and Welfare. Comprehensive survey of living conditions, 2018. Available: https://www.mhlw.go.jp/toukei/ saikin/hw/k-tyosa/k-tyosa18/dl/02.pdf

14 Huyse FJ, Lyons JS, Stiefel FC, et al. "INTERMED": a method to assess health service needs. Gen Hosp Psychiatry 1999;21:39-48.

15 Stiefel FC, de Jonge P, Huyse FJ, et al "INTERMED": a method to assess health service needs. Gen Hosp Psychiatry 1999;21:49-56.

16 de Jonge P, Huyse FJ, Stiefel FC, et al. INTERMED-a clinical instrument for biopsychosocial assessment. Psychosomatics 2001;42:106-9.

17 Kishi Y, Matsuki M, Mizushima H, et al. The INTERMED Japanese version: inter-rater reliability and internal consistency. $J$ Psychosom Res 2010;69:583-6.

18 Peek CJ, Baird MA, Coleman E. Primary care for patient complexity, not only disease. Fam Syst Health 2009;27:287-302. 
19 Maxwell M, Hibberd C, Pratt R, et al. Development and initial validation of the Minnesota Edinburgh complexity assessment method (MECAM) for use within the keep well health check, 2011. Available: http://www.healthscotland.com/uploads/documents/ 18448-DevelopmentOfMinnesotaEdinburghComplexityMethod.pdf

20 Pratt R, Hibberd C, Cameron IM, et al. The patient centered assessment method (PCAM): integrating the social dimensions of health into primary care. J Comorb 2015;5:110-9.

21 Maxwell M, Hibberd C, Pratt R, et al. Patient centred assessment method (PCAM), 2015. Available: https://med.umn.edu/sites/med. umn.edu/files/pcam_assessment_tool_2.0.pdf

22 Yoshida S, Matsushima M, Wakabayashi H, et al. Validity and reliability of the patient centred assessment method for patient complexity and relationship with hospital length of stay: a prospective cohort study. BMJ Open 2017;7:e016175.

23 Yoshida S, Matsushima M, Wakabayashi H, et al. Correlation of patient complexity with the burden for health-related professions, and differences in the burden between the professions at a Japanese regional Hospital: a prospective cohort study. BMJ Open 2019;9:e025176.

24 Nishioka D, Kondo N. Addressing patients' social health risks at hospital: lessons from "social prescribing" activities. Japanese journal of health economics \& policy 2018;30:5-18.

25 Ministry of Health, Labour and Welfare. Establishing the communitybased integrated care system, 2020. Available: https://www.mhlw.go. jp/english/policy/care-welfare/care-welfare-elderly/dl/establish_e.pdf

26 Wild D, Grove A, Martin M, et al. Principles of good practice for the translation and cultural adaptation process for patient-reported outcomes (pro) measures: report of the ISPOR Task force for translation and cultural adaptation. Value Health 2005;8:94-104.

27 World Health Organization. Process of translation and adaptation of instruments, 2019. Available: https://www.who.int/substance_abuse/ research_tools/translation/en/

28 von Elm E, Altman DG, Egger M, et al. Strengthening the reporting of observational studies in epidemiology (STROBE) statement: guidelines for reporting observational studies. BMJ 2007;335:806-8.

29 Miller MD, Ferris DG. Measurement of subjective phenomena in primary care research: the visual analogue scale. Fam Pract Res $J$ 1993;13:15-24.

30 Charlson ME, Pompei P, Ales KL, et al. A new method of classifying prognostic comorbidity in longitudinal studies: development and validation. J Chronic Dis 1987;40:373-83.

31 Charlson ME, Charlson RE, Peterson JC, et al. The Charlson comorbidity index is adapted to predict costs of chronic disease in primary care patients. J Clin Epidemiol 2008;61:1234-40.
32 MacCallum RC, Widaman KF, Zhang S, et al. Sample size in factor analysis. Psychol Methods 1999;4:84-99.

33 Hooper D, Coughlan J, Mullen M. Structural equation modelling: guidelines for determining model fit structural equation modelling: guidelines for determining model fit. Electron $J$ Bus Res Methods 2008;6:53-60.

34 Bland JM, Altman DG. Cronbach's alpha. BMJ 1997;314:572.

35 Dancey C, Reidy J. Statistics without maths for psychology: seventh edition. UK: Pearson Education Limited, 2017: 181-90.

36 StataCorp. Stata statistical software: release 14. College Station, tx 2015.

37 StataCorp. Stata 14 base reference manual. College Station, TX: Stata Press, 2015

38 Muthén M. Mplus software version 8.4. Los Angeles, CA, 2017.

39 Muthén LK, Muthén BO. Mplus user's guide. Eighth edition. Los Angeles, CA: Muthén \& Muthén, 2017.

40 Nutbeam D. Health promotion glossary. Health Promot Int 1998;13:349-64

41 Nutbeam D. Health literacy as a public health goal: a challenge for contemporary health education and communication strategies into the 21st century. Health Promot Int 2000;15:259-67.

42 Ministry of Health, Labour and Welfare. Comprehensive survey of living conditions, 2019. Available: https://www.mhlw.go.jp/toukei/ saikin/hw/k-tyosa/k-tyosa19/index.htm

4343 Bureau of Social Welfare and Public Health, Tokyo Metropolitan Government, Medical Examiner's Office. Statistics of single-person households who died in their homes, 2018. Available: https:// www.fukushihoken.metro.tokyo.lg.jp/kansatsu/kodokushitoukei/ kodokushitoukei30.htm

44 Ministry of Health, Labour and Welfare. Overview of medical service regime in Japan, 2019. Available: https://www.mhlw.go.jp/bunya/ iryouhoken/iryouhoken01/dl/01_eng.pdf

45 Ikegami N, Yoo B-K, Hashimoto $\mathrm{H}$, et al. Japanese universal health coverage: evolution, achievements, and challenges. Lancet 2011;378:1106-15

46 Maxwell M, Hibberd C, Aitchison P, et al. The patient centred assessment method for improving nurse-led biopsychosocial assessment of patients with long-term conditions: a feasibility RCT. Health Services and Delivery Research 2018;6:1-120.

47 Danaei G, Ding EL, Mozaffarian D, et al. The preventable causes of death in the United States: comparative risk assessment of dietary, lifestyle, and metabolic risk factors. PLoS Med 2009;6:e1000058.

48 Marmot M, Bell R. Fair Society, healthy lives. Public Health 2012;126 Suppl 1:S4-10. 